AperTO - Archivio Istituzionale Open Access dell'Università di Torino

In vitro and in vivo effects of toceranib phosphate on canine osteosarcoma cell lines and xenograft orthotopic models

This is a pre print version of the following article:

Original Citation:

Availability:

This version is available http://hdl.handle.net/2318/1722333

since 2021-03-05T11:58:53Z

Published version:

DOI:10.1111/vco.12562

Terms of use:

Open Access

Anyone can freely access the full text of works made available as "Open Access". Works made available under a Creative Commons license can be used according to the terms and conditions of said license. Use of all other works requires consent of the right holder (author or publisher) if not exempted from copyright protection by the applicable law. 


\section{Veterinary and Comparative Oncology}

\section{In vitro and in vivo effects of toceranib phosphate in canine osteosarcoma cell lines and xenograft orthotopic models}

\begin{tabular}{|r|l|}
\hline Journal: & Veterinary and Comparative Oncology \\
\hline Manuscript ID & Draft \\
\hline Manuscript Type: & Original Article \\
\hline Keywords: & $\begin{array}{l}\text { Tumor Biology, Tyrosine Kinase, Comparative Oncology, Mouse Models, } \\
\text { In vitro Models }\end{array}$ \\
\hline $\begin{array}{l}\text { Note: The following files were submitted by the author for peer review, but cannot be converted to PDF. } \\
\text { You must view these files (e.g. movies) online. }\end{array}$ \\
\hline supplemnary video 1.avi \\
\hline
\end{tabular}

\section{SCHOLARONE Manuscripts}




\title{
In vitro and in vivo effects of toceranib phosphate in canine osteosarcoma cell lines and xenograft orthotopic models
}

\begin{abstract}
Canine osteosarcoma (OSA) is the most common primary malignant bone tumour with a high metastatic rate and poor prognosis. Toceranib phosphate (TOC) (Palladia ${ }^{\circledR}$, Zoetis, U.S.A.) is a veterinary tyrosine kinase inhibitor (TKI) that selectively inhibits VEGFR-2, PDGFRs and c-Kit, but its efficacy in canine OSA is not fully understood. Here, we evaluated the functional effects of TOC on six OSA cell lines by transwell, wound healing and colony formation assays. Subsequently, two cell lines (Wall and Penny) were selected and inoculated in mice by intra-femur injection, developing an orthotopic xenograft model of canine OSA. For each cell line, 30 mice were injected, half of them used as control and the other half treated with TOC at $40 \mathrm{mg} / \mathrm{kg}$ body weight for 20 days; then mice were sacrificed and subjected to necroscopy. TOC inhibited cellular growth in all the cell lines and reduced invasion and migration in Penny and Wall cell lines. Significantly, TOC treatment decreased tumour growth only in mice inoculated with Penny. Moreover, specific transcripts of PDGFRs and c-Kit resulted down-regulated in these tumours. Immunohistochemical studies demonstrated a significant reduction of Ki67 in treated mice when compared to controls. Results obtained demonstrated that TOC is able to slightly inhibit cell growth in vitro, while its effect is evident only in Penny's xenograft model, where TOC significantly reduced tumour dimension and proliferating index without modifying apoptosis markers and mitotic index. These data may open a new scenario in canine OSA treatment and patient selection based on TKI targets expression.
\end{abstract}




\section{Introduction}

Considering the high similarity at clinical, histopathological and molecular level, spontaneous tumours in dog are considered potential models for human diseases, representing an alternative to rodents for studying cancer biology and therapy ${ }^{1,2}$. Canine osteosarcoma (OSA) represents the most common primary malignant bone tumour, accounting for more than $80 \%$ of all bone tumours, being locally aggressive, and characterized by a high metastatic potential and poor prognosis ${ }^{1,3,4}$. Furthermore, the role of several tyrosine kinases receptors (TKRs) in the pathogenesis of canine OSA has recently been demonstrated ${ }^{5-7}$, as well as the opportunity to use tyrosine kinase inhibitors (TKI) against specific targets ${ }^{8,9}$.

TKI have radically changed the treatment approach and prognosis in several human tumours 10,11 ; also in veterinary medicine this class of molecules resulted promising in few cancer histotypes ${ }^{12-15}$. Toceranib phosphate (TOC) (Palladia ${ }^{\circledR}$, Zoetis, U.S.A) is a specific veterinary TKI that selectively inhibits VEGFR-2, PDGFRs and c-Kit and is currently approved for treatment of mast cell tumours ${ }^{16,17}$. However, there is increasing evidence that other solid tumours such as anal sac, head-neck and thyroid carcinomas, and OSA can be successfully treated with $\mathrm{TOC}^{18-19}$. Although, a recent clinical trial showed controversial results when using Palladia ${ }^{\circledR}$ as a single agent in canine metastatic OSA ${ }^{20}$.

Xenograft mouse models represent important tools to investigate the in vivo response to cancer therapeutic interventions. Previously published canine OSA mouse models were heterotopic and obtained implanting OSA cells intramuscularly (IM) or subcutaneously $(\mathrm{SC})^{21-23}$, however intrinsic limitations were evident such as OSA cells were not exposed to the constitutive microenvironment. Consequently, the biological behaviour of the xenograft tumour and its response to therapy might have not completely reflected the disease progress. Orthotopic mouse models represent a more reliable 
approach to evaluate tumour progression and pharmacological treatment efficacy. As mentioned previously, the clinical use of TOC in canine OSA is still scientifically argued and further investigations are needed. Considering the relevance of canine OSA both in veterinary medicine and comparative oncology, the aims of this study were to evaluate the functional effects of TOC in primary OSA cell lines and to develop orthotopic mice models of canine OSA. In addition, mRNA and protein changes of the preferential targets of TOC, as well as the clinical response, were also evaluated in vivo.

\section{Material and Methods}

Cell lines and cell culture

Seven primary canine OSA cell lines ("Penny", "Wall", "Desmond", "Sky", "Dark", "Lord" and "Pedro"), previously established by Maniscalco et al. $(2013)^{6}$, were used in this study. All cell lines were maintained in Iscove's standard medium supplemented with $10 \%$ foetal bovine serum (FBS), $1 \%$ glutamine, $100 \mu \mathrm{g} / \mathrm{mL}$ penicillin and $100 \mu \mathrm{g} / \mathrm{mL}$ streptomycin, cultured at $37^{\circ} \mathrm{C}$ in a humidified atmosphere of $5 \% \mathrm{CO}_{2}$, and passaged upon reaching confluence. A normal osteoblastic cell line (OSB) was isolated from a healthy dog using a procedure described before ${ }^{5}$.

\section{Transwell assay}

The migration capability of the OSA cell lines was evaluated as follows. Cells were trypsinized, resuspended in Iscove's standard medium and counted in Bürker chambers. Subsequently, $1.5 \times 10^{4}$ cells were resuspended in $200 \mu \mathrm{l}$ of supplemented Iscove's standard medium and added to the non-coated upper chamber of a transwell with $8 \mu \mathrm{m}$ pore size filter (Corning Coster, Cambridge, MA, USA). To test the effects of TOC on the migratory capability of canine OSA cell lines, $800 \mu$ l of supplemented Iscove's standard medium with $1 \mu \mathrm{M}$ of TOC was added to the lower chamber (treated groups) of the wells. 
For controls, $800 \mu$ l supplemented Iscove's standard medium without TOC was added. After 48 hours incubation, cells on the upper side of the filter were mechanically removed with a cotton swab, and both cells migrated to the lower side of the transwell and those that reached the bottom of the wells were incubated with $5 \mu \mathrm{g} / \mathrm{mL}$ Hoechst 33342 (Sigma Diagnostic, St Louis, MO, USA) in $1 \mathrm{~mL}$ culture medium at $37^{\circ} \mathrm{C}$ under $5 \% \mathrm{CO}_{2}$ for 20 minutes, rinsed with PBS (Phosphate Buffer Solution) for 10 minutes 3 times. Both the filter and the bottom of the wells were photographed with a fluorescent equipped microscope at 100x and cells were counted using ImageJ software. Analysis was run in triplicate.

\section{Wound healing assay}

Considering the results obtained by transwell assay, Penny and Wall cell lines were selected for the mobility assay. After trypsinization, $2 \times 10^{5}$ cells/well were plated in a 6 wells plates to grow. When the confluence was reached, the monolayer was wounded by applying a manual scratch and using a sterile $20 \mu \mathrm{L}$ pipette tip. The cellular debris was removed with a gentle wash with complete medium and the supplemented Iscove's medium with $1 \mu \mathrm{M}$ of TOC (treated groups) or without TOC (control groups) was added to the cells. The ability of the cells to repair the wound was evaluated by real time microscopy for 48 hours. Cell migration was monitored using a Leica AF6000 LX (Leica Microsystems, Wetzlar, Germany) inverted microscope equipped with a Leica DFC350FX digital camera and the photographs were taken every 30 minutes for 48 hours. The distance between two parallel lines was measured in 5 different areas along the length of the wound and the analysis was run in duplicate.

\section{Colony formation assay}

Penny and Wall were resuspended in 0.4\% type VII low melting agarose in DMEM (10\% FBS) at $2 \times 10^{4}$ cells/well, plated on a layer of $0.8 \%$ agarose in Iscove's medium 
(10\% FBS) in 6-well culture plates and cultured at $37^{\circ} \mathrm{C}$ with $5 \% \mathrm{CO}_{2}$. After 24 hours, the medium was removed and replenished with fresh medium with $1 \mu \mathrm{M}$ of TOC (treated groups) or without TOC (control groups). The medium was changed every 3 days and after 3 weeks, colonies $>100 \mu \mathrm{m}$ and $<100 \mu \mathrm{m}$ in diameter were counted with an inverted phasecontrast microscope. Colony formation assays were repeated in triplicates.

Cell growth assay

Penny and Wall cell lines were plated in 6-well plates and grown until $90 \%$ of confluence (highly proliferating), then detached and counted in a Bürker chamber. A total of 3000 cells were seeded in 6-well plates till attachment at a maximum of 6 hours, and TOC was added to the treated wells at $1 \mu \mathrm{M}$ concentration. After 72 hours, cells were rinsed with PBS and incubated with $5 \mu \mathrm{g} / \mathrm{mL}$ Hoechst 33342 (Sigma Diagnostic, St Louis, $\mathrm{MO}, \mathrm{USA}$ ) in $1 \mathrm{~mL}$ culture medium at $37^{\circ} \mathrm{C}$ under $5 \% \mathrm{CO}_{2}$ for 20 minutes. Cells were then rinsed again with PBS, observed under a fluorescent microscope at 100x and nuclei were counted using ImageJ software.

\section{Orthotopic xenograft mouse model}

A total of 60 female $n u / n u$ mice, 4-5 week-old, purchased by Charles River Laboratories (Calco, Milan) were housed under pathogen free condition with a $12 \mathrm{~h}$ light/12h dark schedule, fed autoclaved standard chow and water ad libitum. Mice were manipulated and housed according to protocols approved by the XXX University Bioethical Committee and the Italian Ministry of Health (Authorization receipt n. 149401894128). For the intra-femur injections, exponentially growing cells (Penny and Wall) were harvested, counted and resuspended in PBS to a final concentration of $1 \times 10^{7} \mathrm{cells} / \mathrm{ml}$. The animals were anesthetized with zolazepam/tiletamine $(45 \mathrm{mg} / \mathrm{kg})$ and xylazine $(7.5 \mathrm{mg} / \mathrm{kg})$. The knee of the mouse was fixed beyond $90^{\circ}$ and $1 \times 10^{6}$ cells resuspended in $100 \mu$ of PBS were injected into the distal femur using a 25-gauge needle. On day 0, 30 mice were 
injected using Penny and Wall, respectively. Twice a week, mice were monitored to determine the appearance and/or clinical signs of the engrafted tumour. When an average tumour size of $0.5 \mathrm{~cm}$ in the largest diameter was obtained, daily treatment with TOC or vehicle was initiated. Mice were randomly assigned into each group. According to literature, mice were administered once daily with TOC at $40 \mathrm{mg} / \mathrm{kg}$ body weight in citrate buffered ( $\mathrm{pH} 3.5$ ) solution 24,25 for 20 days by oral gavage using rigid dosing cannula. Control mice were treated only with citrate buffered saline administered with the same procedure. Tumour growth was evaluated twice a week by measuring the tumour size by a caliper. Tumour length $(\mathrm{L})$ and width $(\mathrm{W})$ were measured to calculate tumour volume $(\mathrm{V})$ as follows: $\left(L \times W^{2}\right) / 2$. Contextually, body weight was also measured. Five mice were not inoculated and used as body weight control.

Mice were checked up to 20 days post-treatment or till animal endpoint criteria were reached (ill thrift, visible lameness, pain or severe weight loss), then they were humanely euthanized by an intravenous overdose injection of sodium pentobarbital. At post-mortem examination the tumours were excised and cut into two pieces to be frozen in liquid nitrogen for RNA extraction and fixed in $10 \%$ neutral buffered formalin for routine histological exam and immunohistochemistry.

RNA extraction and quantitative reverse transcription PCR (RT-qPCR) expression analysis

Total RNA from all the OSA cell lines and OSB, as well as from engrafted tumours, was extracted using $1 \mathrm{ml}$ of TRIReagent (Sigma-Aldrich) and any residual genomic DNA was removed using a DNAse I Recombinant RNAse free kit (Roche, Mannheim, Germany). RNA concentration was determined by spectrophotometry (BioPhotometer, Eppendorf, Hamburg, Germany). The ratio of the optical densities measured at 260 and $280 \mathrm{~nm}$ was $>1.9$ for all RNA samples. cDNA was synthesized from $1 \mu \mathrm{g}$ of total RNA by RT High-Capacity cDNA Reverse Transcription Kit (Applied Biosystems, Foster City, CA, 
USA), according to the manufacturer's protocol. To determine the relative amounts of specific PDGFRa, PDGFR , VEGFR2 and c-Kit transcripts, RT-qPCR was performed using the CFX Connect Real-Time PCR System (Bio-Rad, Hercules, CA, USA). Primers for target and reference genes were designed on Canis Familiaris GenBank messenger RNA (mRNA) sequences using Primer 3 Software (version 4.0). Oligonucleotides were designed to cross the exon/exon boundaries to minimize the amplification of contaminant genomic DNA and were analyzed using the IDT tool (available at http://www.idtdna.com/scitools/scitools.aspx) for hairpin structure and dimer formation. Primer specificity was verified with BLAST analysis against the genomic NCBI database. Multiple housekeeping genes were selected among 5 potential internal control mRNAs in the dog (HPRT, GAPDH, RP13a, RP18s and RP32) and on the basis of efficiency value GAPDH was selected as the most suitable for the purpose.

Supplementary Table 1 summarizes the primer information, sequences, gene accession number and amplicon sizes. Real-time PCR parameters were: cycle $1,95^{\circ} \mathrm{C}$ for $30 \mathrm{~s}$; cycle 2, $95^{\circ} \mathrm{C}$ for $10 \mathrm{~s}, 60^{\circ} \mathrm{C}$ for $30 \mathrm{~s}$ for 40 cycles. Gene Expression was calculated using the

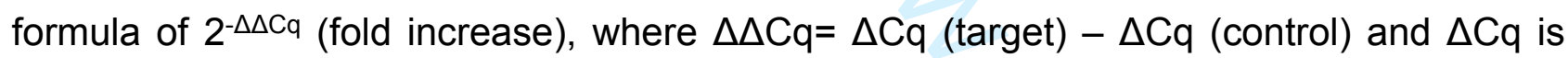
the $\mathrm{Cq}$ of the target gene subtracted from the $\mathrm{Cq}$ of the housekeeping gene.

\section{Histopathological and Immunohistochemical analysis}

Systemic organs and tumours obtained from mice were fixed in $10 \%$ buffered formalin for 24 hours. When needed, tumours were decalcified in 10\% formic acid, and procedures for histological examination were applied. Also, several histological parameters were selected and scored (see Supplementary Table 2).

Immunohistochemistry $(\mathrm{IHC})$ was performed on $4 \mu \mathrm{m}$ thick paraffin sections derived from OSA originated in mice using an automated immunostainer (DAKO). After blocking peroxidase activity and heat-induced antigen retrieval, sections were incubated with Ki67, 
c-Kit and caspase 3 antibodies (see supplementary Table 3). Positive immunostaining for Ki67 was determined by counting 1000 cells in 10 high power randomly-selected neighbouring, non-overlapping fields. The number of Ki67-positive and negative cells was assessed by image analysis using ImageJ freeware and the number of positive cells was expressed as the percentage of positively stained cells in the total number of cells ${ }^{26}$. Immunohistochemical evaluation of caspase 3 was carried out by taking images at $x 40$ microscope objective from 10 random fields per tumour, to provide an average index of caspase 3 positive cells ${ }^{27}$. For the IHC evaluation of c-Kit expression, the specimens were scored according to both the percentage of positively stained tumour cells and their immunostaining intensity ${ }^{28}$.

Statistical analysis

$\mathrm{IHC}$ results were grouped into contingency tables and analyzed using Fisher's exact test or $\mathrm{X}^{2}$ test while $\mathrm{q}-\mathrm{PCR}$ and in vitro data assays were analyzed using Student's $\mathrm{t}$ test. Data were analyzed using MedCalc Statistical Software version 13.3 (MedCalc Software bvba). A p value lower than 0.05 was considered statistically significant.

\section{Results}

\section{TOC inhibits OSA cell migration in vitro}

The effect of TOC on OSA cells migration was assessed by transwell migration and wound healing assays. All the canine OSA cell lines showed the ability to migrate through the membrane and to attach to the lower side. Few cells detached and reached the bottom of the wells. Conversely, TOC treatment reduced OSA cell migration to the bottom of the membrane, within a range from $26.5 \pm 11.6 \%$ (Penny) to $88.1 \pm 1.1 \%$ (Sky; Fig. 1a). Inhibition of cells attachment by TOC ranged from $32 \pm 0.9 \%$ (Wall) to $93 \pm 15.7 \%$ (Lady; Fig. 1b). Representative images of Hoescht stained nuclei in untreated controls and TOC 
treated cells are shown in Figure 1c. Wound healing assay showed a similar inhibitory effect in TOC treated OS cell lines (Supplementary Video 1). The migration rate was decreased to $43.9 \pm 24.8 \%$ in Penny (Fig. 2a) and $71.0 \pm 14.3 \%$ in Wall (Fig. 2b). Considering these preliminary results, Penny and Wall were selected for the following in vitro and in vivo experiments.

\section{TOC inhibits cell growth and anchorage-independent OSA cell growth in vitro}

To assess the growth effect of TOC, Penny and Wall were exposed to TOC for 72 hours. TOC treatment reduced cell growth by $14.6 \pm 2.5 \%$ and $32.16 \pm 4.2 \%$ in Penny and Wall, respectively. To investigate OSA cells growth on anchorage-independent conditions, a colony formation assay was performed. Both cell lines formed colonies when grown resuspended in agarose, but TOC treatment in Penny and Wall slightly decreased colony numbers compared to untreated cells (Fig. 3a). Thereby, when considering exclusively the colonies $>100 \mu \mathrm{m}$ in diameter, TOC treatment showed a higher inhibition of colony formation, with a reduction of $37.7 \pm 8.0 \%$ for Penny and $85.7 \pm 12.0 \%$ for Wall (Fig. $3 b$ ).

\section{TOC reduces in vivo tumour growth only in Penny xenograft model}

To evaluate the activity of TOC in vivo, we generated two orthotopic xenograft mouse models using Penny and Wall. Both cell lines were tumorigenic and primary tumours were macroscopically visible 18 days after injection in $85 \%$ of mice $(n=51)$ with a volume of approximately $3-4 \mathrm{~mm}^{3}$. TOC treatment was started at 22 days post-inoculation and finished at day 42. The experimental design and the time lines of the treatment are shown in Figure 4a. Six mice engrafted with Penny (20\%) and 3 mice engrafted with Wall (10\%) didn't develop tumours at any time, also confirmed at necropsy. Drug-related side effects were observed after 3-4 days of treatment including dermatitis in $5(33.3 \%)$ and 4 (26.7\%) mice inoculated with Penny and Wall, respectively. However, TOC significantly decreased tumour growth in mice inoculated with Penny, but not with Wall cell line (Fig. 
4b). Also, no differences in body weight between the four different groups were evident (Fig. 4c).

\section{TOC treatment reduces PDGFRa, PDGFR , VEGFR2 and c-Kit mRNA expression in} both in vivo and in vitro models

Quantitative RT-PCR results (Fig. 5a) revealed that all the OSA cell lines had a higher mRNA expression of both PDGFRa and PDGFR $\beta$ compared to the OSB control cell line $(P<0,05)$. The only exception was Dark cell line for PDGFRa. VEGFR2 and c-Kit mRNAs were increased in 3 out of 7 OS cell lines (Penny, Wall and Lord) when compared to the OSB cell lines $(P<0,05)$. Finally, we examined PDGFRa, PDGFR $\beta$, VEGFR2 and cKit mRNA expression in tumours obtained from TOC treated and control mice. A significant down regulation of PDGFRa, PDGFR $\beta$ and c-Kit in mice inoculated with Penny and treated with TOC compared to controls was found, confirming in vitro results (Fig. 5b), whereas no differences were retrieved in mice inoculated with Wall (Fig. 5b).

\section{TOC treatment influences tumour cell density and KI-67 score}

Histological examination of the xenograft tumors confirmed a chondroblastic OSA from Penny (Fig. 6A) and osteoblastic productive OSA (Fig. 6B) from Wall ${ }^{7}$. No differences for anisocytosis, anisokaryosis, presence of haemorrhages, vascular invasion, bone marrow invasion or muscular invasion were found after treatment. Notably, the grade of anisocytosis and anisokaryosis was always elevated (Fig. 6C) in association with necrotic-haemorrhagic areas (Fig. 6D). Conversely, bone marrow invasion occurred in 12/51 tumours (23\%) (Fig. 6E); muscular invasion in 48/51 samples (93\%) (Fig. 6F), but no differences were found between the two groups. Of note, in the only mouse of the study (belonging to the Wall control group) in which vascular invasion was diagnosed, presence of lung metastasis was also observed (Fig.6G). 
Histologically, TOC-treated Penny and Wall xenograft models had a decrease of tumour cell density when compared to vehicle-treated animals ( $p=0.015$ and $p=0.03$, respectively). Although the differences were not significant, a trend towards a decrease in the amount of matrix and necrosis was observed after TOC treatment both in tumours originated from Penny and Wall. By immunohistochemistry, tumours from TOC treated mice showed a lower Ki-67 score (Fig.6H) when compared to tumours grown in vehicle-treated mice (Fig.6I). Also, a significant reduction of cellular density was obtained both in Penny and Wall engrafted tumours $(p<0.005)$. Conversely, Caspase 3 expression was not influenced by TOC treatment.

\section{Discussion}

OSA represents the most common primary malignant bone tumour in dog, with a high metastatic potential and poor prognosis ${ }^{1,29}$. In humans, this disease is still scarcely curable with a high rate of metastasis. ${ }^{30,31}$ Comparative oncology studies have shown many similarities between OSA occurring in human and canine patients, and also in veterinary oncology the development of xenograft models ${ }^{32}$ in mice represents nowadays an important alternative to investigate the microenvironment and the molecular mechanisms driving cancer growth, as well as to evaluate the biological effects of novel therapeutic agents such as TKIs.

In our study, we developed an orthotopic model of canine OSA and further tested the biological and pharmacological effects of TOC. To identify the most promising cell line, TKRs targets of TOC were firstly evaluated by RT-qPCR in seven canine OS cell lines. All of them showed an heterogenous amount of mRNA that was gene dependent. Interestingly, similar variations were previously described when considering protein $6,33,34$. 
Cell lines were further investigated by several biological assays in order to determine whether cell migration was affected by treatment with TOC. Transwell assay demonstrated that all the OSA cell lines were able to migrate in absence of chemoattractive factors; conversely migration was negatively affected by TOC, although to a different extent among cell lines. Interestingly, Penny and Dark resulted the most sensitive to TOC treatment using the proliferating assay, while the migration score was the highest in Penny and the lowest in Wall. Wound healing migration rate, colony formation and cell growth rate in soft agar assays revealed that both Penny and Wall were negatively affected by TOC treatment. Overall, these in vitro results suggested that Wall and Penny responded to TOC treatment by slightly reducing their migration and proliferating behaviour. This might be due to the ability of TOC to inhibit the kinase activity of the target receptors and consequently the downstream activated pathways, as demonstrated in previous results obtained by other authors where AG1296 induced down regulation of pAKT in time and dose dependence $6,35,36$.

To validate the in vitro results, both Penny and Wall cell lines were inoculated in an orthotopic model, and the cellular growth of OSA was monitored. Results demonstrated that both Penny and Wall cells were highly tumorigenic, showing engraftment after 18 days. Also, tumour histology confirmed that both cell lines conserved the original morphological features. Interestingly, TOC treatment decreased the tumour growth in mice inoculated with Penny but not with Wall. Regarding the selected histological parameters, tumour cell density was reduced in treated mice compared to control mice independently from the cell line origin. It is worth noting that vascular invasion as well as lung metastasis was reported only in one mouse from Wall control group. This observation, even with several limitations, suggests a possible inhibitory effect on the metastatic spread by TOC as shown in the metastatic DARK cell line that resulted more sensitive to the TOC 
treatment. Unfortunately, this observation cannot be confirmed statistically due to the low number of occurrences. With regard to this aspect, it could be speculated that the metastatic process is mediated by the microenvironment that develops within the orthotopic model and that possibly depends on VEGFR2 expression, as recently demonstrated in human OSA ${ }^{37}$. No mRNA expression modifications for PDGFRs, VEGFR2 and c-Kit were found in tumours removed from control versus TOC-treated mice, implying that TOC treatment did not act at the transcriptional level of these genes.

Ki67 results demonstrated a lower proliferation index $(\mathrm{PI})$ in TOC treated tumours than in the ones of control mice (in both Penny and Wall groups). This data indicate a TOC effect in decreasing tumour proliferation, but not on cell apoptosis, as shown by caspase-3 results. Interestingly, Sunitinib (SU11248) is the equivalent of TOC in humans being administered in patients with gastrointestinal stromal tumours (GIST), neuroendocrine tumours and renal carcinomas, while is off-label in human $\mathrm{OSA}^{38}$ and recently it was tested in xenograft models of human OSA cell lines showing an evident reduction of the tumour growth and PI, thereby mimicking our results ${ }^{39}$.

Today, clear indications for using TOC in canine OS treatment are not available, and recent clinical trials do not support the use of TOC as a single agent therapy for canine metastatic $\mathrm{OS}^{20,40}$. Moreover, the use of TOC in c-Kit mutated mast cell tumours was also recently discussed ${ }^{41}$. Our results demonstrate that $\mathrm{TOC}$ is able to inhibit cell growth in vitro only mildly, while its effect is more relevant in xenograft models. Considering the relevant expression of PDGFRs, c-Kit and VEGFR2 in Penny, these data suggest that TOC treatment might be more effective in tumours expressing these targets. Further studies are needed to test the efficacy of this molecule in canine OSA, but these results open a new scenario where only a subset of OS having high target levels might respond to TOC treatment. 


\section{Bibliografia}

1. Morello E, Martano M, Buracco P. Biology, diagnosis and treatment of canine appendicular osteosarcoma: Similarities and differences with human osteosarcoma. Veterinary Journal. 2011;189(3):268-277.

2. Withrow SJ, Powers BE, Straw RC, Wilkins RM. COMPARATIVE ASPECTS OF OSTEOSARCOMA - DOG VERSUS MAN. Clinical Orthopaedics and Related Research. 1991(270):159-168.

3. Farese JP, Kirpensteijn J, Kik M, et al. Biologic Behavior and Clinical Outcome of 25 Dogs with Canine Appendicular Chondrosarcoma Treated by Amputation: A Veterinary Society of Surgical Oncology Retrospective Study. Veterinary Surgery. 2009;38(8):914-919.

4. Casteleyn C, Sleeckx N, De Spiegelaere W, Heindryckx F, Coulon S, Van Steenkiste C. New therapeutic targets in veterinary oncology: Man and dog definitely are best friends. Veterinary Journal. 2013;195(1):6-7.

5. De Maria R, Miretti S, lussich S, et al. met oncogene activation qualifies spontaneous canine osteosarcoma as a suitable pre-clinical model of human osteosarcoma. J Pathol. 2009;218(3):399408.

6. Maniscalco L, lussich S, Morello E, et al. PDGFs and PDGFRs in canine osteosarcoma: New targets for innovative therapeutic strategies in comparative oncology. Veterinary Journal. 2013;195(1):4147.

7. Maniscalco L, lussich S, Morello E, et al. Increased expression of insulin-like growth factor-1 receptor is correlated with worse survival in canine appendicular osteosarcoma. Vet J. 2015;205(2):272-280.

8. Mantovani FB, Morrison JA, Mutsaers AJ. Effects of epidermal growth factor receptor kinase inhibition on radiation response in canine osteosarcoma cells. BMC Vet Res. 2016;12:82.

9. Fahey CE, Milner RJ, Kow K, Bacon NJ, Salute ME. Apoptotic effects of the tyrosine kinase inhibitor, masitinib mesylate, on canine osteosarcoma cells. Anticancer Drugs. 2013;24(5):519-526.

10. Hojjat-Farsangi M. Small-molecule inhibitors of the receptor tyrosine kinases: promising tools for targeted cancer therapies. Int J Mol Sci. 2014;15(8):13768-13801.

11. Wu P, Nielsen TE, Clausen MH. FDA-approved small-molecule kinase inhibitors. Trends Pharmacol Sci. 2015;36(7):422-439.

12. Downing S, Chien MB, Kass PH, Moore PE, London CA. Prevalence and importance of internal tandem duplications in exons 11 and 12 of c-kit in mast cell tumors of dogs. Am J Vet Res. 2002;63(12):1718-1723.

13. Amagai $Y$, Tanaka A, Matsuda A, et al. Heterogeneity of internal tandem duplications in the c-kit of dogs with multiple mast cell tumours. J Small Anim Pract. 2013;54(7):377-380.

14. London CA. Small molecule inhibitors in veterinary oncology practice. Vet Clin North Am Small Anim Pract. 2014;44(5):893-908.

15. London CA. Tyrosine kinase inhibitors in veterinary medicine. Top Companion Anim Med. 2009;24(3):106-112.

16. Robat $\mathrm{C}$, London $\mathrm{C}$, Bunting $\mathrm{L}$, et al. Safety evaluation of combination vinblastine and toceranib phosphate (Palladia(R)) in dogs: a phase I dose-finding study. Vet Comp Oncol. 2012;10(3):174-183.

17. London CA, Malpas PB, Wood-Follis SL, et al. Multi-center, placebo-controlled, double-blind, randomized study of oral toceranib phosphate (SU11654), a receptor tyrosine kinase inhibitor, for the treatment of dogs with recurrent (either local or distant) mast cell tumor following surgical excision. Clin Cancer Res. 2009;15(11):3856-3865.

18. London C, Mathie T, Stingle N, et al. Preliminary evidence for biologic activity of toceranib phosphate (Palladia((R))) in solid tumours. Vet Comp Oncol. 2012;10(3):194-205.

19. Gardner HL, London CA, Portela RA, et al. Maintenance therapy with toceranib following doxorubicin-based chemotherapy for canine splenic hemangiosarcoma. BMC Vet Res. 2015;11:131. 
20. Laver T, London CA, Vail DM, Biller BJ, Coy J, Thamm DH. Prospective evaluation of toceranib phosphate in metastatic canine osteosarcoma. Vet Comp Oncol. 2017.

21. Coomer AR, Farese JP, Milner R, et al. Development of an intramuscular xenograft model of canine osteosarcoma in mice for evaluation of the effects of radiation therapy. Am J Vet Res. 2009;70(1):127-133.

22. Farese JP, Fox LE, Detrisac CJ, Van Gilder JM, Roberts SL, Baldwin JM. Effect of thalidomide on growth and metastasis of canine osteosarcoma cells after xenotransplantation in athymic mice. Am J Vet Res. 2004;65(5):659-664.

23. Hong SH, Kadosawa T, Mochizuki M, Matsunaga S, Nishimura R, Sasaki N. Effect of all-trans and 9cis retinoic acid on growth and metastasis of xenotransplanted canine osteosarcoma cells in athymic mice. Am J Vet Res. 2000;61(10):1241-1244.

24. London CA, Hannah AL, Zadovoskaya R, et al. Phase I dose-escalating study of SU11654, a small molecule receptor tyrosine kinase inhibitor, in dogs with spontaneous malignancies. Clin Cancer Res. 2003;9(7):2755-2768.

25. Mendel DB, Laird AD, Xin X, et al. In vivo antitumor activity of SU11248, a novel tyrosine kinase inhibitor targeting vascular endothelial growth factor and platelet-derived growth factor receptors: determination of a pharmacokinetic/pharmacodynamic relationship. Clin Cancer Res. 2003;9(1):327-337.

26. Dolka I, Sapierzynski R, Krol M. Retrospective study and immunohistochemical analysis of canine mammary sarcomas. BMC Vet Res. 2013;9:248.

27. McCleese JK, Bear MD, Fossey SL, et al. The novel HSP90 inhibitor STA-1474 exhibits biologic activity against osteosarcoma cell lines. Int J Cancer. 2009;125(12):2792-2801.

28. Miiji LN, Petrilli AS, Di Cesare S, et al. C-kit expression in human osteosarcoma and in vitro assays. Int J Clin Exp Pathol. 2011;4(8):775-781.

29. Morello E, Martano M, Buracco P. Biology, diagnosis and treatment of canine appendicular osteosarcoma: similarities and differences with human osteosarcoma. Vet J. 2011;189(3):268-277.

30. Ferguson WS, Goorin AM. Current treatment of osteosarcoma. Cancer Invest. 2001;19(3):292-315.

31. Vormoor B, Knizia HK, Batey MA, et al. Development of a preclinical orthotopic xenograft model of ewing sarcoma and other human malignant bone disease using advanced in vivo imaging. PLoS One. 2014;9(1):e85128.

32. Guan G, Lu Y, Zhu X, et al. CXCR4-targeted near-infrared imaging allows detection of orthotopic and metastatic human osteosarcoma in a mouse model. Sci Rep. 2015;5:15244.

33. Maniscalco L, lussich S, Morello E, et al. Increased expression of insulin-like growth factor-1 receptor is correlated with worse survival in canine appendicular osteosarcoma. Veterinary Journal. 2015;205(2):272-280.

34. Gattino F, Maniscalco L, lussich S, et al. PDGFR-alpha, PDGFR-beta, VEGFR-2 and CD117 expression in canine mammary tumours and evaluation of the in vitro effects of toceranib phosphate in neoplastic mammary cell lines. Vet Rec. 2018.

35. Yancey MF, Merritt DA, Lesman SP, Boucher JF, Michels GM. Pharmacokinetic properties of toceranib phosphate (Palladia, SU11654), a novel tyrosine kinase inhibitor, in laboratory dogs and dogs with mast cell tumors. J Vet Pharmacol Ther. 2010;33(2):162-171.

36. Halsey $\mathrm{CH}$, Gustafson DL, Rose BJ, et al. Development of an in vitro model of acquired resistance to toceranib phosphate (Palladia(R)) in canine mast cell tumor. BMC Vet Res. 2014;10:105.

37. Zheng B, Ren T, Huang Y, Guo W. Apatinib inhibits migration and invasion as well as PD-L1 expression in osteosarcoma by targeting STAT3. Biochem Biophys Res Commun. 2018;495(2):16951701.

38. Demetri GD, van Oosterom AT, Garrett CR, et al. Efficacy and safety of sunitinib in patients with advanced gastrointestinal stromal tumour after failure of imatinib: a randomised controlled trial. Lancet. 2006;368(9544):1329-1338. 
39. Kumar RM, Arlt MJ, Kuzmanov A, Born W, Fuchs B. Sunitinib malate (SU-11248) reduces tumour burden and lung metastasis in an intratibial human xenograft osteosarcoma mouse model. Am J Cancer Res. 2015;5(7):2156-2168.

40. Laver T, London CA, Vail DM, Biller BJ, Coy J, Thamm DH. Prospective evaluation of toceranib phosphate in metastatic canine osteosarcoma. Vet Comp Oncol. 2018;16(1):E23-e29.

41. Weishaar KM, Ehrhart EJ, Avery AC, et al. c-Kit Mutation and Localization Status as Response Predictors in Mast Cell Tumors in Dogs Treated with Prednisone and Toceranib or Vinblastine. $J$ Vet Intern Med. 2018;32(1):394-405. 

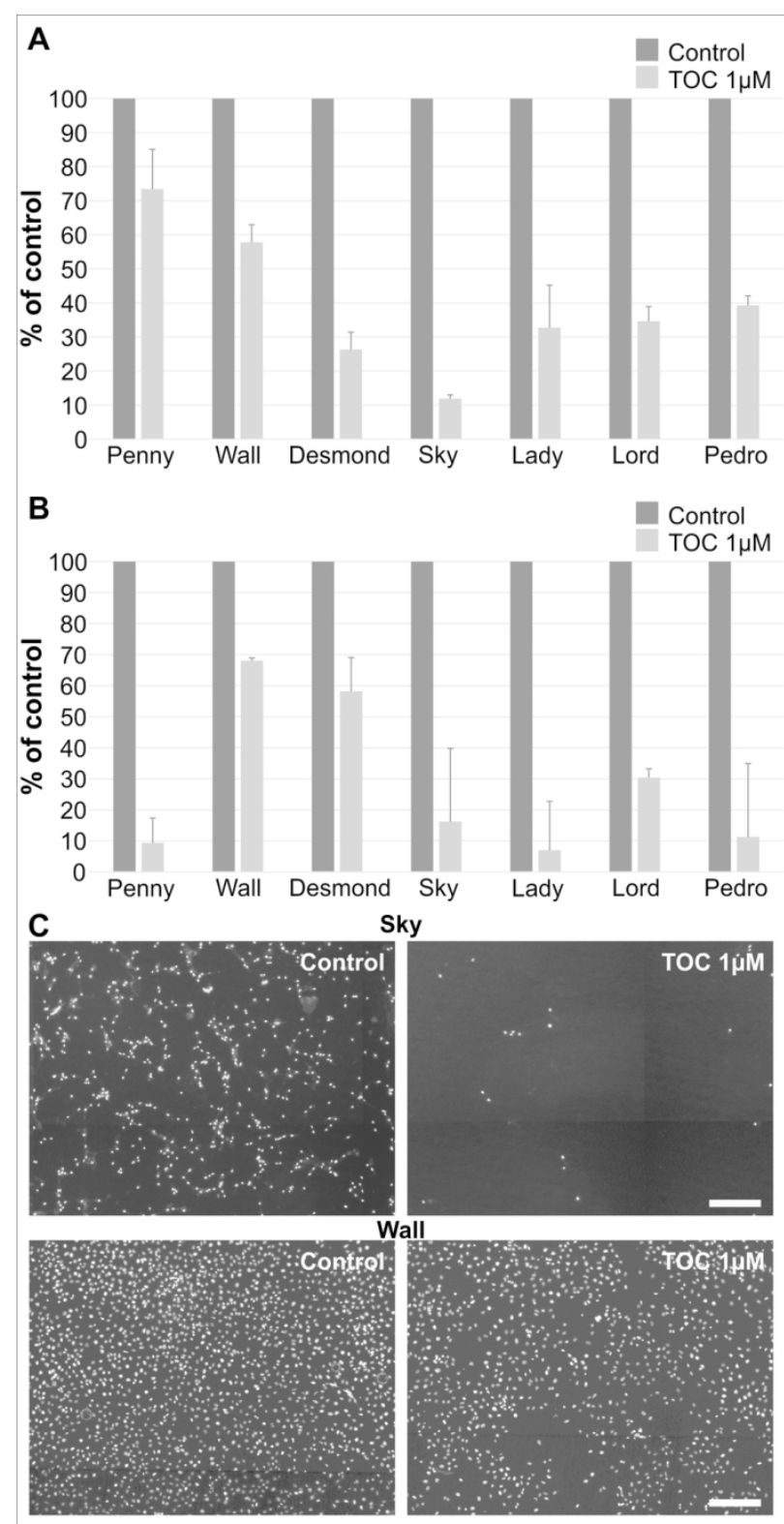

$80 \times 156 \mathrm{~mm}(300 \times 300 \mathrm{DPI})$ 


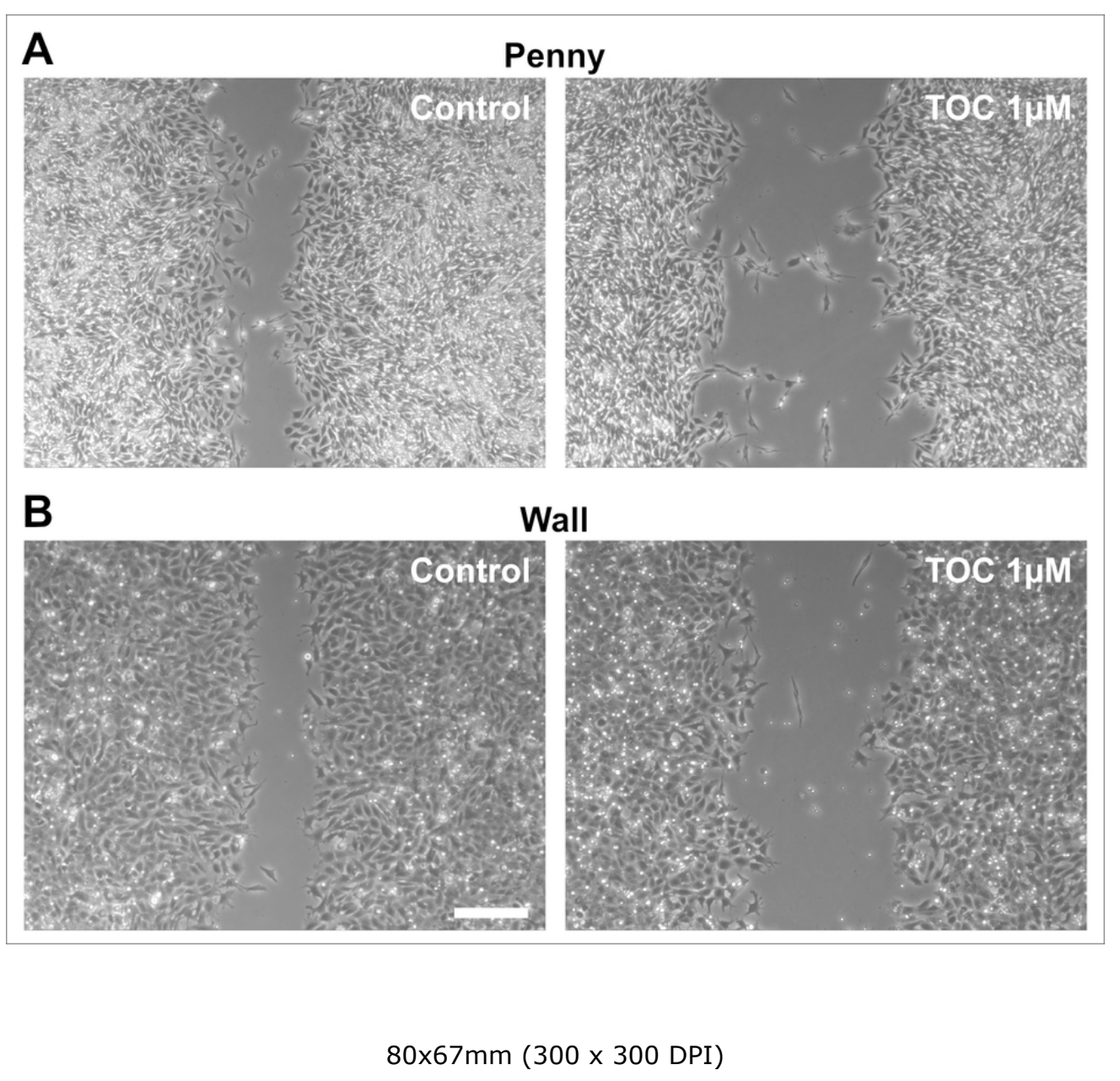




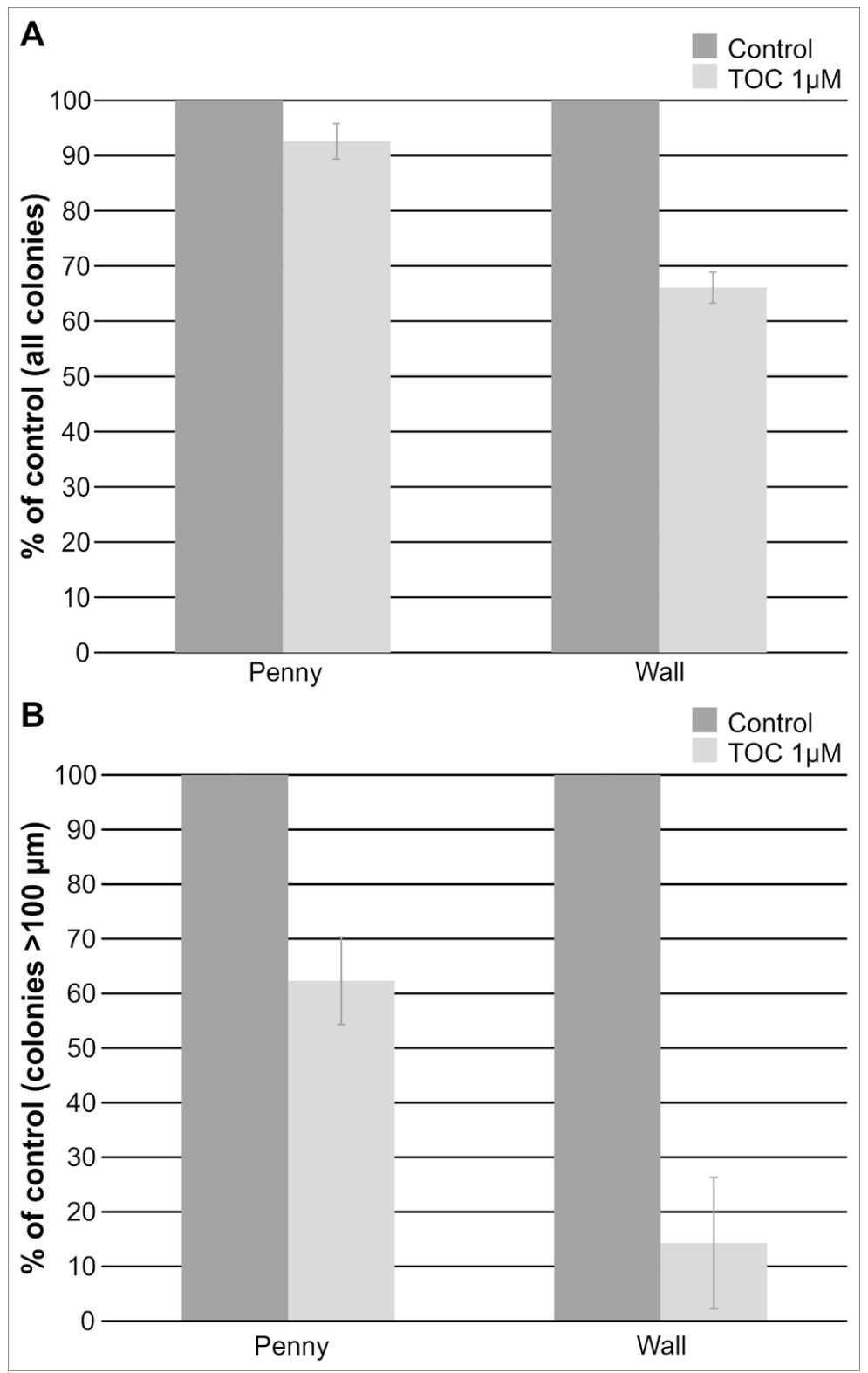

$80 \times 127 \mathrm{~mm}(300 \times 300 \mathrm{DPI})$ 


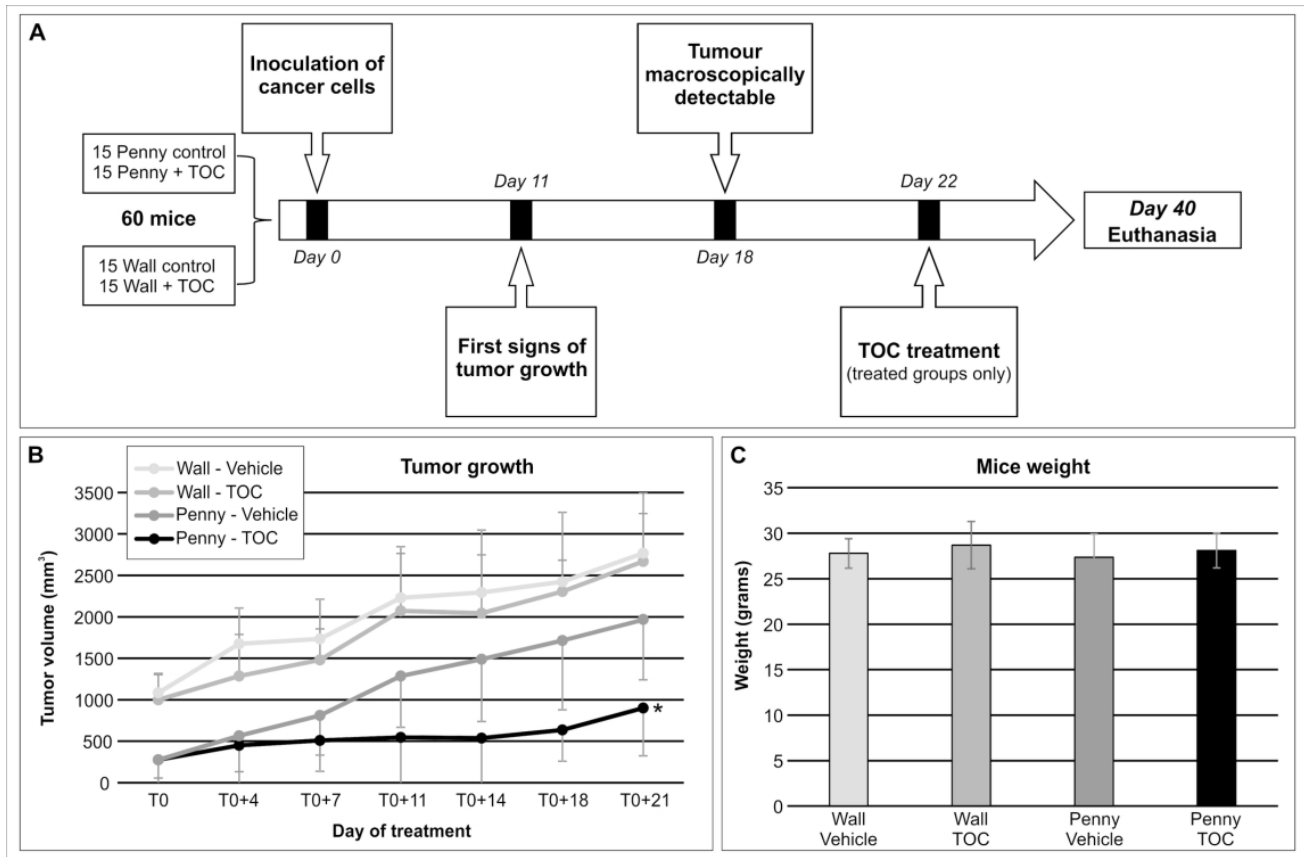

$180 \times 118 \mathrm{~mm}(300 \times 300$ DPI $)$

\footnotetext{
Veterinary and Comparative Oncology
} 


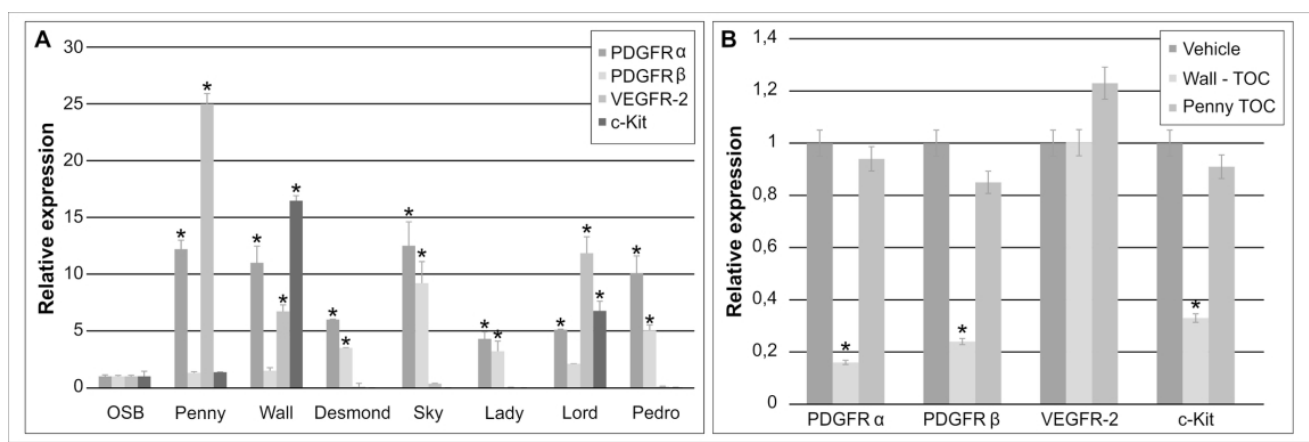

$180 \times 59 \mathrm{~mm}(300 \times 300 \mathrm{DPI})$

1

2

3

4

5

6

7

8

10

11

12

13

14

15

16

17

18

19

20

21

22

23

24

25

26

27

28

29

30

31

32

33

34

35

36

37

38

39

40

41

42

43

44

45

46

47

48

49

50

51

52

53

54

55

56

57

58

59

60

Veterinary and Comparative Oncology 


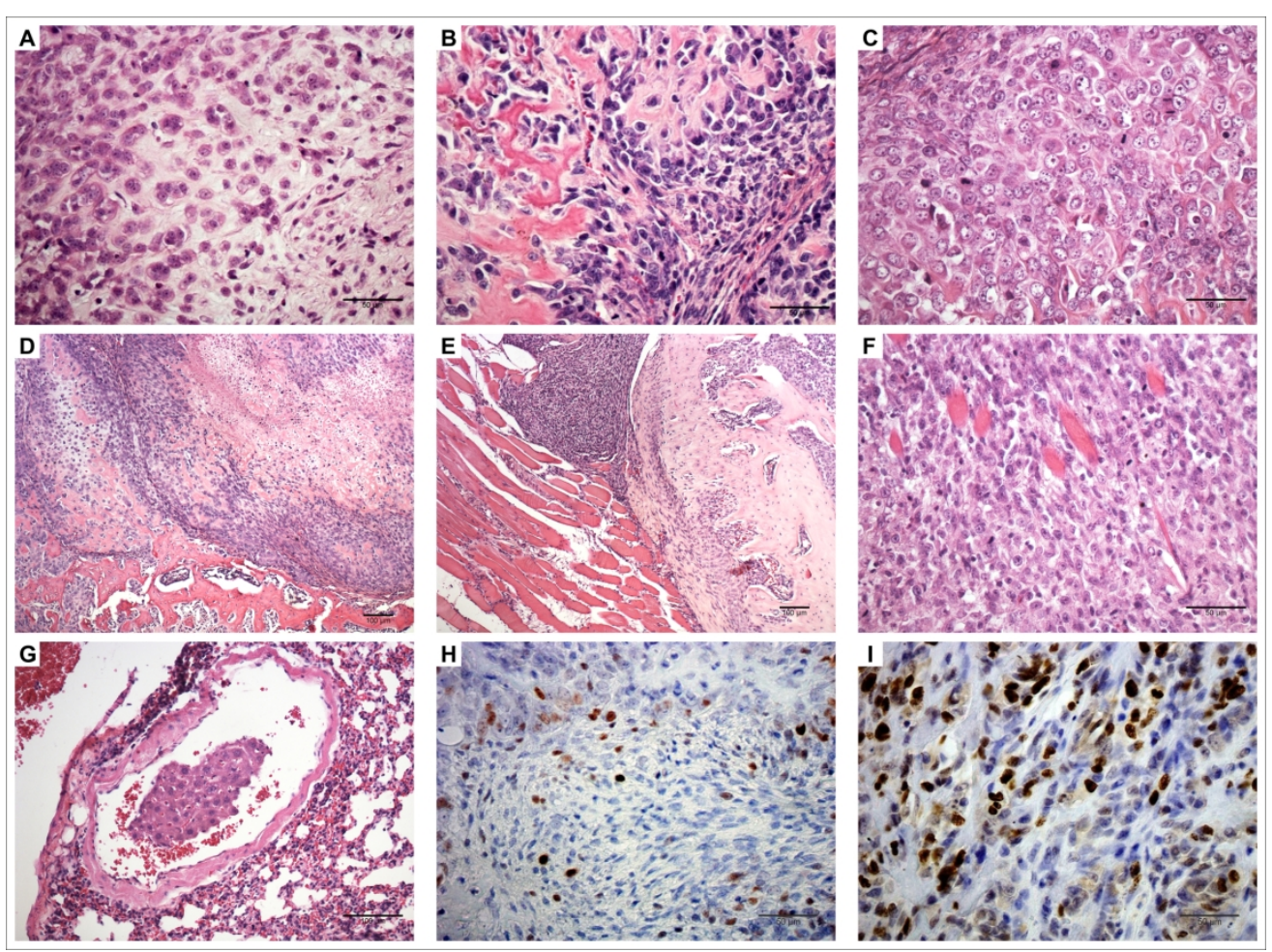

$180 \times 133 \mathrm{~mm}(300 \times 300 \mathrm{DPI})$ 


\section{LEGENDS TO FIGURES}

Figure 1.

Cellular migration by transwell assay. (A) Percentage of cells attached to the lower side of the membrane and $(B)$ the bottom of the lower chamber in all canine OSA cell lines treated with Toceranib $(1 \mu \mathrm{M})$ compared to the control (untreated). Error bars represent standard deviation of experimental triplicates. (C) Immunofluorescence assay showing cells migrated to the bottom of the lower chamber in Sky and Wall cell lines treated with TOC compared to the untreated cell lines (Hoescht staining) $(200 x$, Scale bar $=250 \mu \mathrm{m})$.

\section{Figure 2.}

Wound Healing Migration Assay. Penny cell line (A) and Wall cell line (B) after 48h of treatment with TOC $(1 \mu \mathrm{M})$ with respectively not treated cell lines. $(400 \mathrm{x}$, Scale bar= $100 \mu \mathrm{m})$.

Figure 3.

Colony Formation Assay. (A) Percentage of colonies formed in agarose in Penny and Wall cell lines treated with TOC $1 \mu \mathrm{M}$ compared to the untreated cells. (B) Percentage of colonies (>100 $\mu$ m diameter) formed in agarose in Penny and Wall cell lines treated with TOC $1 \mu \mathrm{M}$. Error bars represent standard deviation of experimental triplicates.

\section{Figure 4.}

Experimental Xenograft Design. (A) Experimental timeline of OSA xenograft on mice and TOC treatment. (B) Measurements of tumour volume of xenografts of Wall or Penny cell lines in mice, along the treatment with TOC and with a vehicle (from T0 to T0+21days). As shown in the figure mice inoculated with Penny cells and treated with TOC showed a significant smaller tumour volume compared to those treated with a vehicle $\left({ }^{*} p<0.05\right)$. (C) Weight of mice with Wall or Penny xenografts, treated with TOC or with vehicle, at the end of the experiment. No variation between the groups is highlighted.

Figure 5.

Quantitative PCR. (A) Expression of PDGFR- $\alpha$, PDGFR- $\beta$, VEGFR-2 and c-Kit transcripts in primary osteosarcoma (OSA) cell lines. PDGFR- $\alpha$ mRNA were expressed at higher levels in 7/7 OSA cell lines, PDGFR- $\beta$ in 4/7, VEGFR-A transcript had a higher expression 
in 4/7 OSA cell lines and c-Kit in 2/7, compared to the normal cell line (OSB) $\left({ }^{*} p<0.05\right)$. The fold increase of each specific mRNA was normalised with normal OSB cell line and the error bars indicate the standard deviation of experimental triplicates. (B) Expression by quantitative PCR of PDGFR- $\alpha$, PDGFR- $\beta$, VEGFR-2 and c-Kit in primary Wall and Penny OS cell lines treated with TOC, compared to the control (untreated). Wall cell line showed a lower expression of PDGFR- $\alpha$, PDGFR- $\beta$ and $c-K i t$ when treated $\left({ }^{*} p<0.05\right)$. Penny cell did not show any significant variation. The fold increase of each specific mRNA was normalised with the control cell line and the error bars indicate the standard deviation of experimental triplicates.

Figure 6.

Histological features of osteosarcoma xenografts. (A) Penny cell line xenograft showing chondroblastic. Neoplastic cells have a chondrocyte-like morphology and are located within lacunae. H\&E stain (400x, bar= $50 \mu \mathrm{m})$. (B) Wall cell line xenograft showing, osteoblastic hystotype Neoplastic cells surrounded by irregular trabeculae of osteoid matrix. H\&E stain (400x, bar= $50 \mu \mathrm{m})$ and (C) Marked anisocytosis and anisokaryosis. (D) Necrosis involving the $30 \%$ of the neoplastic tissue. $(200 x$, scale bar $=100 \mu \mathrm{m})$. (E) Bone marrow invasion (200x, scale bar $=100 \mu \mathrm{m})$. $(F)$ Muscular invasion (200x, scale bar=

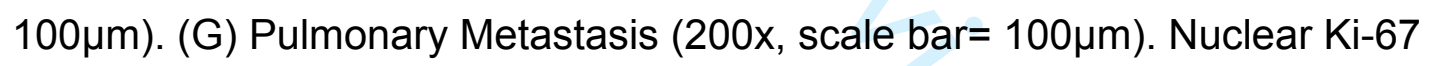
immunolabelling respectively in Penny xenograft $(\mathrm{H})$ treated with TOC and not treated mice (I). Streptavidin-biotin-peroxidase method. Mayer's haematoxylin counterstain (400x, bar= $50 \mu \mathrm{m}$ ). 


\section{Supplementary Table 1.}

Primer sequences employed in q-PCR

\begin{tabular}{lll}
\hline Primer & Gene & Sequence \\
\hline Forward & VEGFR-2 & 5'-CATGCACGGTCTACGCCGTCC-3' \\
Reverse & VEGFR-2 & 5'-CAGCTTGGGCGGGCTTGTAGG-3' \\
Forward & CD117 & 5'-CTCGCGGCGCCTGGGATTTT-3' \\
Reverse & CD117 & 5'-GAAGAGCCTGTCCGGACGCC-3' \\
Forward & PDGFR- $\alpha$ & 5'-CATCCCCCTGCCCGACATCG-3' \\
Reverse & PDGFR- $\alpha$ & 5'-TGAGCTGTGTCTGTTCTTCTTGCC-3' \\
Forward & PDGFR- $\beta$ & 5'-GTCCTCAAAGGCCAGGCACTGTGG-3' \\
Reverse & PDGFR- $\beta$ & 5'-CCCCGGGGGTGTGATGACCAG-3' \\
Forward & GAPDH & 5'-GGCACAGTCAAGGCTGAGAAC-3' \\
Reverse & GAPDH & 5'-CCAGCATCACCCCATTTGAT-3' \\
\hline
\end{tabular}


Supplementary Table 2.

Histological parameters and scores for histological examination of tumours xenograft

\begin{tabular}{|l|l|}
\hline \multicolumn{1}{|c|}{ PARAMETER } & \\
\hline Anisokaryosis and $^{\text {anisocytosis }}{ }^{1}$ & $0=$ no variation \\
& $1=$ mild variation \\
& $2=$ moderate variation \\
& $3=$ marked variation \\
\hline Tumour cell density & $1=<25 \%$ of cells \\
& $2=25-50 \%$ of cells \\
& $3=50-75 \%$ of cells \\
& $4=>75 \%$ of cells \\
\hline Mitotic Index ${ }^{1}$ & Number of mitosis in 10 high-power fields (400x) \\
\hline Amount of matrix ${ }^{2}$ & $1=>50 \%$ matrix \\
& $2=25-50 \%$ matrix \\
\hline Amount of necrosis & $3=<25 \%$ matrix \\
\hline Haemorrage & $0=$ no necrosis \\
& $1=<25 \%$ of necrosis \\
& $2=15-50 \%$ of necrosis \\
& $3=>59 \%$ of necrosis \\
\hline Invasion of the bone & $0=$ absence of haemorrage \\
& $1=$ presence of haemorrage \\
\hline Invasion of the bone marrow & $0=$ absence of invasion \\
& $1=$ bone invasion \\
\hline Invasion of the muscle & $1=$ bone marrow invasion \\
\hline & $0=$ absence of invasion \\
\hline & $1=$ muscle invasion \\
\hline
\end{tabular}

1. Kruse MA, Holmes ES, Balko JA, Fernandez S, Brown DC, Goldschmidt MH. Evaluation of clinical and histopathologic prognostic factors for survival in canine osteosarcoma of the extracranial flat and irregular bones. Vet Pathol. 2013;50(4):704-708.

2. Kirpensteijn J, Kik M, Rutteman GR, Teske E. Prognostic significance of a new histologic grading system for canine osteosarcoma. Vet Pathol. 2002;39(2):240-246. 
Table 1.

Antibodies used in immunohistochemistry

\begin{tabular}{lllc}
\hline Antibody & \multicolumn{1}{c}{ Type } & \multicolumn{1}{c}{ Source } & Concentration \\
\hline Ki67 & Mouse monoclonal & Dako, Burlingame, CA, USA & $1: 75$ \\
Caspase-3 & Rabbit polyclonal & R\&D systems, Minneapolis, MN, USA & $1: 250$ \\
c-Kit & Rabbit polyclonal & Dako, Burlingame, CA, USA & $1: 750$ \\
\hline
\end{tabular}

